\title{
Pengaruh Kepadatan Bagan Dan Kedalaman Perairan Terhadap Produktivitas Hasil Tangkap Bagan Tancap Di Teluk Pang Pang, Banyuwangi, Jawa Timur
}

\author{
Rani Ekawaty ${ }^{a *}$ \\ ${ }^{a}$ Program Studi Manajemen Sumberdaya Perairan, Fakultas Kelautan dan Perikanan, Universitas Udayana, Bali, Indonesia \\ * Penulis koresponden. Tel.: +62-361-702-802 \\ Alamate-mail: rani.ekawaty@gmail.com
}

\begin{abstract}
During 1998-2003 fisheries production tends to decrease for Muncar, Banyuwangi, East Java. Growing number of fishing gears (especially the set fishing gear like the bambbo platform lift net) in the Pang Pang bay even though its presence is not allowed, this is might be the caused of the decreased fisheries production. As for the bamboo platform lift net itself has many factors that affect the catch effort productivity. Some of them were examined in this study which are the density (unit/ha), water depth (m) and time of hauling (min). From this study, we expected to know how far the influence of each factors as well as the mathematical models of it. This study results shows that the density of the bamboo platform lift net greatly affect the fishing gear productivity, that the higher the density number will lead to further decline in the fishing gear productivity. The water depth also has an effect, in which the deeper the waters of the fishing gear, the more catch result get. The other factors such as the time dummy and hauling time influence less on the catch. The optimum density number is $<5$ unit/ha, as the optimum water depth is $\geq 26,2 \mathrm{~m}$.
\end{abstract}

Keywords: density; water depth; hauling time; time dummy; bamboo platform lift net

\section{Pendahuluan}

Sebagai Negara kepulauan (archipelagic state) yang besar, Indonesia memiliki wilayah teritorial perairan laut seluas 3,1 juta $\mathrm{km} 2$. Di samping itu Indonesia memiliki pula hak dan tanggung jawab atas pemanfaatan dan pengelolaan zona ekonomi eksklusif (ZEE atau EEZ) seluas 2,5 juta $\mathrm{km}^{2}$, sehingga luas seluruh wilayah perairan laut di bawah yurisdiksi Indonesia menjadi 5,6 juta $\mathrm{km} 2$ (Birowo, 2001).

Sebagian besar wilayah Indonesia terdiri dari perairan yang diperkirakan mencapai $2 / 3$ dari seluruh wilayah Indonesia. Meskipun Indonesia termasuk ke dalam wilayah tropis ternyata secara geografis perairannya tidak homogen tetapi memiliki karakteristik yang berbeda. Indonesia memiliki wilayah perairan pantai, teluk, selat, laut dan laut lepas (samudera). Perairan di Samudera Hindia tentunya memiliki karakteristik yang berbeda dengan perairan Laut Jawa. Dengan karakteristik yang berbeda ini mengakibatkan tipe perikanan yang ada di masing-masing wilayah perairan berbeda. Jenis alat tangkap yang digunakan sudah tentu mengikuti ketersediaan sumber daya ikan yang ada di wilayah perairan tersebut (Widianto, 2001).

Selat Bali merupakan perairan berbentuk corong yang subur, perikanan hampir bersifat mono-spesies dan monogear, hasil tangkap utama ikan lemuru, alat tangkap purse seine, industri pengolahan sudah sangat berkembang, dan tingkat eksploitasi cenderung over-fishing.

Muncar merupakan daerah dengan potensi perikanan cukup tinggi. Selama kurun waktu kurang lebih dua tahun terakhir di Muncar, produksi hasil tangkap untuk alat tangkap bagan tancap semakin menurun (istilah lokal oleh nelayan setempat disebut dengan "laib") seiring dengan semakin bertambah banyaknya jumlah unit alat tangkap bagan tancap yang beroperasi terutama di perairan dalam Teluk Pang Pang, Muncar dimana kepadatan alat tangkapnya semakin tinggi.

Bagan tancap merupakan alat tangkap berskala kecil (mandiri) dimana seharusnya keberadaannya dilarang berdasarkan SK Bupati Banyuwangi tahun 1980 dengan 3 alasan, yaitu : 1) Bagan tancap adalah alat tangkap menetap; 2) Mengganggu alur pelayaran; 3) Sisa-sisa bambuo dari bagan tancap yang roboh dapat merusak jaring.

Tetapi kenyataan yang ada alat tangkap ini justru semakin bertambah dengan alasan factor ekonomi, nelayan banyak yang memilih alat tangkap ini. Sedangkan informasi mengenai kepadatan yang diperbolehkan dalam rangka untuk menjaga potensi lestari sangatlah terbatas, sehingga merupakan salah satu faktor penghambat pengambilan keputusan yang efektif menyangkut sumberdaya ikan.

Dari uraian tersebut menunjukkan bahwa perlu dilakukan suatu penelitian tentang pengaruh kepadatan dan kedalaman terhadap produktivitas alat tangkap bagan tancap agar dapat mendapatkan informasi mengenai faktor-faktor apa sajakah yang berpengaruh dalam rangka pengelolaan sumberdaya perikanan di wilayah perairan Selat Bali Banyuwangi Propinsi Jawa Timur. 


\section{Metode Penelitian}

\subsection{Lokasi Penelitian}

Penelitian ini dilaksanakan di perairan Teluk Pang Pang/Sembulungan Muncar Banyuwangi Jawa Timur. Gambar 1 menyajikan lokasi penetian.

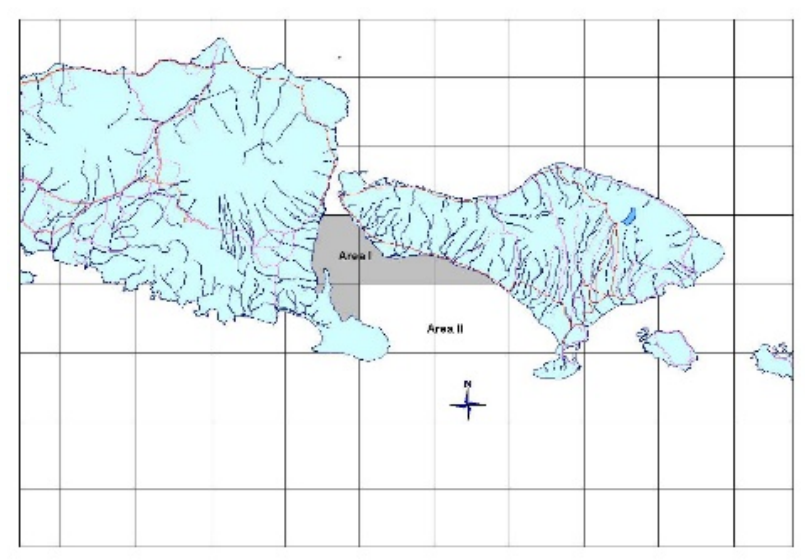

Gambar 1. Lokasi Penelitian

\subsection{Metode Penelitian}

Penelitian ini dilakukan di perairan Teluk Pang Pang / Tanjung Sembulungan Muncar Banyuwangi Jawa Timur. Berdasarkan Laporan Satatistik Perikanan Propinsi Jawa Timur tahun 2002, jumlah armada tangkap yang menggunakan alat tangkap bagan tancap berjumlah 142 unit. Untuk perolehan data menggunakan metode simple random sampling atau sampling acak sederhana, diambil 12 sampel / responden, dengan rincian 6 sampel pada wilayah zona I (luar Teluk Pang-pang) dan 6 sampel lainnya pada wilayah zona II (dalam Teluk Pang-pang).

Pengumpulan data primer dilakukan secara langsung oleh peneliti dengan ikut langsung melaut, dengan menggunakan GPS untuk dapat mengetahui titik-titik lokasi letak bagan tancap. Selain itu dibantu oleh nelayan bagan tancap yang melakukan penangkapan, mereka diwawancarai untuk mengisi form survey berisi data yang meliputi: nama pemilik, kedalaman, lama operasi penangkapan, hasil tangkapan,dll. Peneliti juga langsung terlibat langsung dalam pengumpulan data mengenai hasil tangkapan dan konstruksi alat tangkap agar data yang diperoleh dapat lebih lengkap guna mendapatkan data yang dibutuhkan.

Pada pengambilan data primer dibedakan antara waktu bulan terang dan waktu bulan gelap, sebenarnya hal ini mempengaruhi lama operasi penangkapan, tetapi untuk nelayan alat tangkap bagan tancap hal ini dianggap tidak mempengaruhi, karena nelayan bagan tancap tetap melakukan operasi penangkapan di waktu bulan terang, berbeda dengan nelayan alat tangkap lain seperti purse seine dan payang. Sedangkan pembagian waktu bulan terang dan bulan gelap adalah : untuk tanggal 21-9 adalah waktu bulan gelap, untuk tanggal 10-20 adalah waktu bulan terang (dengan catatan : pada penanggalan bulan Jawa).
Data sekunder yang dikumpulkan diperoleh dari instansi terkait antara lain: Laporan Dinas Perikanan maupun Laporan Statistik Perikanan yang digunakan sebagai pedoman untuk mengetahui nama serta banyaknya alat tangkap dilokasi penelitian, serta data yang lain dari BPPI Muncar.

\subsection{Metode Analisis Data}

Setelah data dari lapang yang diperlukan terkumpul, maka data disusun dan dianalisa. Data hasil tangkapan pada masing-masing daerah operasi penangkapan dari form data produksi harian (Lampiran 2) tersebut, dianalisa dengan metode statistik. Suatu uji statistik dapat dikatakan terbaik, apabila uji tersebut mampu menghasilkan kesimpulan $\mathrm{H}_{0}$ ditolak manakala $\mathrm{H}_{0}$ tidak benar. Oleh karena itu jika data penelitian memenuhi persyaratan untuk deselesaikan dengan metode parametrik, maka uji statistik parametrik merupakan pilihan uji terbaik (Muhammad, 1991).

Berdasarkan faktor-faktor yang ada diduga sebagai berikut :

a. Dummy

Bahwa hasil tangkap dipengaruhi oleh waktu-waktu penangkapan (terang bulan atau gelap bulan), dugaan sementara hasil tangkap lebih banyak pada saat gelap bulan.

\section{b. Kedalaman}

Bahwa hasil tangkap dipengaruhi oleh kedalaman, dugaan sementara bahwa makin dalam bagan tancap maka makin banyak hasil tangkapnya.

c. Jarak

Bahwa hasil tangkap dipengaruhi oleh jarak alat tangkap bagan tancap dari pantai, dugaan sementara makin jauh jarak bagan dari pantai maka makin banyak hasil tangkapnya.

d. Kepadatan

Bahwa hasil tangkap dipengaruhi oleh kepadatan, dugaan sementara adalah makin tinggi angka kepadatan alat tangkap bagan tancap maka semakin sedikit hasil tangkapnya.

e. Lama operasi penangkapan

Bahwa hasil tangkap dipengaruhi oleh lama operasi penangkapan yaitu waktu lama penarikan jaring keatas. Dugaan sementara adalah makin lama operasi penangkapan maka makin sedikit hasil tangkapnya.

Pada penelitian ini data dianalisa menggunakan analisis regresi dari hasil komputasi menggunakan program SPSS, dilanjutkan dengan uji $\mathrm{F}$ dan uji t.

\subsubsection{Model matematis fungsi produksi}

Penelitian ini bertujuan mengetahui hubungan antara faktor-faktor yang mempengaruhi produksi hasil tangkap (X) terhadap hasil tangkap bagan tancap (Y) yang digambarkan dalam fungsi Cobb-Douglas. Peubah tak bebasnya adalah hasil tangkap (produksi) pada alat tangakap bagan tancap dan peubah bebasnya yaitu kepadatan, kedalaman, jarak, lama operasi penangkapan, 
dan dummy waktu terhadap waktu penangkapan pada bulan gelap dan bulan terang.

Pada penelitian ini peubah bebasnya lebih dari satu $\left(\mathrm{X}_{1}, \mathrm{X}_{2}, \ldots \ldots . ., \mathrm{X}_{\mathrm{k}}\right)$ sehingga memungkinkan peubahnya ada yang kuantitatif (berupa angka) dan kualitataif (tidak berbentuk angka). Akan lebih baik jika peubah kualitataifnya dipertimbangkan, cara yang dipergunkan adalah menggunakan peubah dummy (boneka). Dalam penelitian ini dibuat peubah dummy terhadap waktu gelap dan terang bulan, untuk mengetahui hasil tangkap pada saat bulan gelap dan bulan terang. Dengan waktu bulan gelap sama dengan 1 dan waktu bulan terang sama dengan 0 .

Secara matematis model fungsi Cobb-Douglas adalah sebagai berikut :

$\mathrm{Yi}=\mathrm{m} \mathrm{X}_{1 \mathrm{i}}{ }^{\mathrm{b} 1} \mathrm{X}_{2 \mathrm{i}}{ }^{\mathrm{b} 2} \ldots . . \mathrm{X}_{\mathrm{ki}}{ }^{\mathrm{bk}} \mathrm{ei}^{\mathrm{u}}$

Kemudian melalui transformasi log diperoleh persamaan linier :

$\log Y=\log m+b_{1} \log X_{1 i}+b_{2} \log X_{2 i} \ldots . . b_{k} \log X_{k i}+u$

Dimana :

$\mathrm{Y}_{\mathrm{i}} \quad=$ Produksi / hasil tangkap alat tangkap bagan tancap $(\mathrm{Kg})$

$\mathrm{X}_{1 \mathrm{i}}=$ Dummy waktu (bulan gelap dan bulan terang)

$\mathrm{X}_{2 \mathrm{i}}=$ Kedalaman alat tangkap $(\mathrm{m})$

$\mathrm{X}_{3 \mathrm{i}}=$ Jarak alat tangkap dari pantai (mil laut)

$\mathrm{X}_{4 \mathrm{i}}=$ Kepadatan alat tangkap bagan tancap (unit/ha)

$\mathrm{X}_{5 \mathrm{i}}=$ Lama operasi penangkapan (menit)

$\mathrm{m}=$ Intersep (estimasi nilai Y untuk Xi1 dan Xi2 keduanya $=0$ )

$\mathrm{b} \quad=$ koefisien regresi $\mathrm{Y}$ untuk $\mathrm{X}_{\mathrm{i} 1}, \mathrm{X}_{\mathrm{i} 2}, \ldots \ldots \ldots, \mathrm{X}_{\mathrm{i} 5}$ (dimana $X_{i}$ tetap)

$\mathrm{ei}^{\mathrm{u}} \quad=$ kesalaahn acak (galat)

\subsubsection{Model matematis fungsi produksi}

Model analisis fungsi Cobb Douglas, dalam penyelesaian hubungan antara hasil tangkap / produksi (Y) dan faktor-faktor yang mempengaruhi (X) biasanya dengan cara regresi dimana variasi dari $\mathrm{Y}$ dipengaruhi oleh variasi dari $\mathrm{X}$.

Untuk menguji model dan pendugaan parameter yang diperoleh dari pengujian denga fungsi produksi Cobb Douglas digunakan :

a. Uji F

Pengujian dilakukan dengan analisa sidik ragam dengan uji $\mathrm{F}$ dengan kaidah pengujian sebagai berikut :

$$
F_{\text {hitung }}=\frac{J K \text { Regresi } / k}{J K \text { Sisa } / n-k-1}
$$

Kesimpulan uji $\mathrm{F}$ adalah sebagai berikut :

- Jika $\mathrm{F}_{\mathrm{h}}<\mathrm{F}_{\mathrm{t} 5 \%}$, maka $\mathrm{H}_{0}$ diterima dan $\mathrm{H}_{1}$ ditolak, berarti semua peubah bebas tidak berpengaruh terhadap peubah tidak bebas.

- Jika $\mathrm{F}_{\mathrm{h}}>\mathrm{F}_{\mathrm{t} 5 \%}$, maka $\mathrm{H}_{0}$ ditolak dan $\mathrm{H}_{1}$ diterima, berarti semua peubah bebas berpengaruh terhadap peubah tidak bebas.

\section{b. Koefisien Determinasi $\left(\mathrm{R}^{2}\right)$}

Nilai koefisien determinasi menunjukkan seberapa jauh model yang terbentuk dapat menerangkan kondisi yang sebenarnya sebagai ukuran ketepatan garis regresi yang dibuat dari hasil pendugaan terhadap sekelompok data hasil observasi. Makin besar nilai $\mathrm{R}^{2}$, semakin bagus garis regresi yang terbentuk (Sugiarto, 1992).

$$
R^{2}=\frac{J K \text { Regresi }}{J K \text { Total terkoreksi }}
$$

- Jika $\mathrm{R}^{2}=0$, berarti tidak ada hubungan antara $\mathrm{X}$ dan $\mathrm{Y}$, atau model regresi yang terbentuk tidak tepat untuk meramalkan Y.

- Jika $\mathrm{R}^{2}=1$, berarti garis regresi yang terbentuk dapat meramalkan Y secara sempurna.

c. Uji t

Uji t digunakan untuk mengetahui pengaruh peubah bebas dan peubah tidak bebas secara parsial.

$$
\begin{gathered}
T_{\text {hitung }}=\frac{b_{1}}{\sqrt{\operatorname{var}\left(b_{i}\right)}} \\
\text { - Jika } \mathrm{t}_{\text {hitung }}<\mathrm{t}_{\text {tabel }}, \text { maka terima } \mathrm{H}_{0} \\
\text { - Jika } \mathrm{t}_{\text {hitung }}>\mathrm{t}_{\text {tabel }}, \text { maka tolak } \mathrm{H}_{0}
\end{gathered}
$$

\subsection{Definisi Operasional}

a. Produksi / hasil tangkap $\left(\mathrm{Y}_{\mathrm{i}}\right)$ adalah jumlah hasil tangkapan ikan dengan alat tangkap bagan tancap. Data yang digunakan adalah data produksi hasil tangkap bagan tancap setiap satu hari operasi penangkapan dengan satuan $\mathrm{Kg}$.

b. Dummy waktu $\left(\mathrm{X}_{1 \mathrm{i}}\right)$ adalah waktu penangkapan bagan tancap berdasarkan waktu bulan gelap dan waktu bulan terang. Bulan gelap $=1$, bulan terang $=0$.

c. Kedalaman $\left(\mathrm{X}_{2 \mathrm{i}}\right)$ adalah kedalaman bagan tancap dari permukaan air sampai dasar perairan dengan satuan meter.

d. Jarak $\left(\mathrm{X}_{3 \mathrm{i}}\right)$ adalah jarak bagan tancap dari pantai dengan satuan mil laut.

e. Kepadatan $\left(\mathrm{X}_{4 \mathrm{i}}\right)$ adalah kepadatan bagan tancap / ha (dengan asumsi bahwa bila jumlah alat tangkap 4 unit/ha keatas adalah padat) dengan satuan unit/ha.

f. Lama operasi penangkapan $\left(\mathrm{X}_{5 \mathrm{i}}\right)$ adalah lama hauling dari jaring (menarik jaring keatas untuk mendapatkan hasil tangkapan ikan) dengan satuan menit.

\section{Hasil Dan Pembahasan}

\subsection{Deskripsi Alat Tangkap Bagan Tancap di Dusun Kalimati Desa Kedungrejo Kecamatan Muncar}

\subsubsection{Model matematis fungsi produksi}

Jaring bagan tancap di Dusun Kalimati desa Kedungrejo kecamatan Muncar dikenal dengan nama "waring", yaitu jaring yang berupa lembaran-lembaran panjang dengan ukuran lebar 1,10 meter dengan ukuran mata jaring sangat kecil yaitu $0,4 \mathrm{~cm}$. 
Bahan jaring adalah serat nylon atau PA (PolyAmida) monofilament / senar. Serat nylon untuk keperluan perikanan mempunyai kekuatan yang sangat tinggi dengan mulur kecil. Tahan tekukan dan tahan gosokan yang tinggi. Serat nylon tahan terhadap serangan jamur, bakteri dan serangga. Karena kekuatan nylon tinggi, maka sangat baik untuk keperluan perikanan. Benangnya dapat dibuat segala macam alat penangkap ikan yang terbuat dari jaring mulai dari alat-alat yang kecil seperti jaring klitik dan lain-lain sampai yang besar-besar dan modern, seperti jaring lampara, jaring kolor dan jaring trawl. Juga benangnya bisa dijadikan tali pancing tonda dan prawe atau rawai (Anonymous, 1985).

\subsubsection{Tali Temali (Rope) dan Pemberat}

Tali temali yang digunakan pada bagan tancap ini untuk mengikat bambu satu dengan yang lainnya agar saling terkait dengan kencang, selain sebagai tali penarik jaring pada roller. Tali temali dan tali penarik ini terbuat dari bahan PE (Polietilena).

Sifat-sifat serat polietilena yang baik adalah kestabilan kimianya. Tahan terhadap pengaruh kimia seperti alkali, asam, larutan-larutan dan garam-garam organis. Sangat tahan terhadap serangan jamur dan bakteri juga tahan terhadap serangan serangga, larva, ngengat, ganggang, air laut dan berumur panjang (Anonymous, 1985).

Pemberat yang digunakan pada alat tangkap bagan tancap ini adalah batu yang berjumlah empat buah dengan berat masing-masing $\pm 5 \mathrm{Kg}$, yang diikatkan pada tali pada batang bambu yang tersambung pada jaringnya.

\subsection{Hasil Tangkapan}

Hasil tangkapan untuk alat tangkap ini rata-rata adalah ikan-ikan murahan dan biasanya jumlah hasil tangkapnya tidak begitu banyak mengingat alat tangkap ini adalah alat tangkap berskala kecil. Pada saat penelitian ini dilakukan ikan-ikan yang tertangkap dominan adalah ikan petek dan teri, sedangkan ikan hasil tangkap sampingan antara lain rajungan, cumi-cumi, lemuru sempenit dan protolan, tamban, laplap, kocol, sledeng, kacangan, baronang dan kerapu.

Untuk produksi hasil tangkap pada saat penelitian ini dilakukan rata-rata dari semua responden yang ada tidaklah banyak, karena pada saat itu tidak ada ikan (laib). Rata-rata produksi hasil tangkap dari semua responden adalah 19, $88 \mathrm{~kg} /$ trip. Rata-rata hasil tangkap untuk bulan terang dan bulan gelap lebih banyak pada saat bulan gelap, yaitu $15 \mathrm{~kg} /$ trip untuk bulan gelap dan $10,33 \mathrm{~kg} /$ trip untuk bulan terang. Hal ini mungkin dikarenakan jam kerja pada saat bulan gelap lebih panjang / lama dibandingkan jam kerja pada saat bulan terang.

Menurut penuturan para nelayan bagan yang menjadi responden penelitian ini rata-rata produksi hasil tangkap bagan sebelum tahun 2000 dan sesudahnya sangat jauh berbeda. Bila dulu sebelum tahun 2000 produksinya bisa mencapai ton per malam, sekarang dengan mendapatkan $50 \mathrm{~kg}$ keatas saja sulit. Sama halnya dengan ikan hasil tangkapnya, jika dulu mendapatkan ikan lemuru dengan mudahnya, sekarang sudah hampir tidak ada lemuru di
Teluk Pang Pang, yang ada adalah sempenit terkadang protolan, kalaupun ada juga tidak banyak.

Dari uraian tersebut diatas menunjukkan bahwa keadaan perairan Teluk Pang Pang sudah dalam keadaan over fishing, disamping disebabkan oleh kepadatan bagan yang semakin bertambah tiap tahunnya.

\subsection{Analisis Data Hasil Tangkapan}

\subsubsection{Analisis Hubungan Input-Output}

Masukan (input) adalah peubah bebasnya yaitu faktorfaktor yang mempengaruhi hasil tangkap (kepadatan, kedalaman, jarak, lama operasi penangkapan dan dummy waktu). Sedangkan keluaran (output) adalah peubah tak bebasnya yaitu hasil tangkap (produksi) alat tangkap bagan tancap. Analisis ini dimaksudkan untuk mengetahui hubungan dari input dan output dengan menggunakan model analisis fungsi Cobb Douglas. Hubungan antara keduanya dapat dilihat pada Tabel 1 .

\section{Tabel 1}

Hasil Analisis Hubungan Faktor Input-Output Pada Alat Tangkap Bagan Tancap.

\begin{tabular}{clrrl}
\hline No. & \multicolumn{1}{c}{ Variabel } & $\begin{array}{c}\text { Koefisien } \\
\text { regresi }\end{array}$ & \multicolumn{1}{c}{ thitung } & \multicolumn{1}{c}{ Sig. } \\
\hline 1 & Dummy waktu & $-0,125$ & 0,032 & 0,975 \\
2 & Kedalaman & $-8,203$ & 1,058 & 0,305 \\
3 & Kedalaman & 0,236 & 1,154 & 0,264 \\
4 & Kepadatan & $-100,712$ & 2,268 & 0,037 \\
5 & Kepadatan & 10,444 & 1,948 & 0,068 \\
6 & Lama hauling & 0,484 & 0,816 & 0,426 \\
\hline 7 & Konstanta $=319,229$ & & & \\
\hline 8 & F-Hitung $=3,579$ & & & \\
\hline 9 & $\mathrm{R}^{2}=0,55$ & & & \\
\hline 10 & F tabel 5\% $=2,53$ & & & \\
\hline
\end{tabular}

Dari tabel diatas didapatkan sig. (tingkat signifikan) untuk kepadatan alat tangkap bagan tancap adalah 0,037 (nilai ini lebih kecil dari 0,05) yang berarti berbeda nyata, sehingga kepadatan memang berpengaruh nyata terhadap hasil tangkap/produksi alat tangkap bagan tancap. Sedangkan untuk kedalaman perairan tingkat signifikannya sebesar 0,305 ini berarti berpengaruh nyata dengan peluang kesalahan $30,5 \%$, berarti kedalaman alat tangkap bagan tancap berpengaruh terhadap hasil tangkap/produksi alat tangkap bagan tancap tersebut.

Dari hasil analisis diperoleh persamaan regresi model lengkap sebagai berikut :

$\mathrm{Y}=319-8,20 \mathrm{X}_{1}+0,236 \mathrm{X}_{1}{ }^{2}-101 \mathrm{X}_{2}+10,4 \mathrm{X}_{2}{ }^{2}+0,484 \mathrm{X}_{3}-0,12 \mathrm{Z}$

Dimana :

$\mathrm{Y}=$ Produksi/hasil tangkap (Kg/trip)

$\mathrm{X}_{1}=$ Kedalaman perairan alat tangkap bagan tancap (m)

$\mathrm{X}_{2}=$ Kepadatan alat tangkap bagan tancap (unit/ha)

$\mathrm{X}_{3} \quad=$ Lama Hauling (menit)

$\mathrm{Z}=$ Dummy waktu (bulan terang/bulan gelap)

Dari persamaan diatas didapatkan bahwa :

- Koefisien regresi untuk $\mathrm{X}_{2}$ (kepadatan) sebesar -101, maka apabila kepadatan ditambah 1\% akan menurunkan produksi sebesar 101\%. Hal tersebut berarti bahwa kepadatan memang sangat berpengaruh terhadap laju produksi hasil tangkap. 
- Koefisien regresi untuk $X_{1}$ (kedalaman perairan) sebesar -8,20, maka apabila kedalaman ditambah 1\% akan menurunkan produksi sebesar 8,20\%. Kedalaman perairan juga ikut mempengaruhi hasil tangkap dimana juga ikut mempengaruhi hasil tangkap dimana semakin dalam maka akan menurunkan hasil tangkap.

- Sedangkan untuk lama hauling, koefisien regresi untuk $\mathrm{X}_{3}$ (lama hauling) sebesar 0,484, maka apabila lama hauling ditambah $1 \%$ akan meningkatkan produksi sebesar $0,484 \%$.

\subsubsection{Analisis Hubungan Input-Output}

a. Produksi dengan kedalaman perairan

Dari data hasil produksi terlihat bahwa dimana dugaan sebelum penelitian bahwa semakin dalam perairan pada unit alat tangkap makan semakin banyak hasil tangkapnya, namun yang terlihat dari data adalah kedalaman kurang berpengaruh terhadap hasil tangkap atau produksi (Gambar 2). Hal tersebut disebabkan oleh banyak faktor yang tidak tentu dan tidak bisa dikontrol seperti faktor alam.

Dari persamaan hubungan tunggal antara produksi $(\mathrm{Y})$ dengan kedalaman perairan $\left(\mathrm{X}_{2}\right)$ diatas didapatkan bahwa dalam keadaan konstan $(\mathrm{X}=0)$ produksi hasil tangkap bernilai positif. Didapatkan juga bahwa makin dalam kedalaman perairan maka makin banyak hasil tangkapnya. Didapatkan juga bahwa nilai intersenya positif yang berarti makin dalam kedalaman perairan maka makin banyak produksi hasil tangkapnya.

b. Produksi dengan Kepadatan

Dari data hasil produksi terlihat bahwa makin tinggi angka kepadatan maka makin sedikit hasil tangkap (produksi) alat tangkap bagan tancap (Gambar 3).

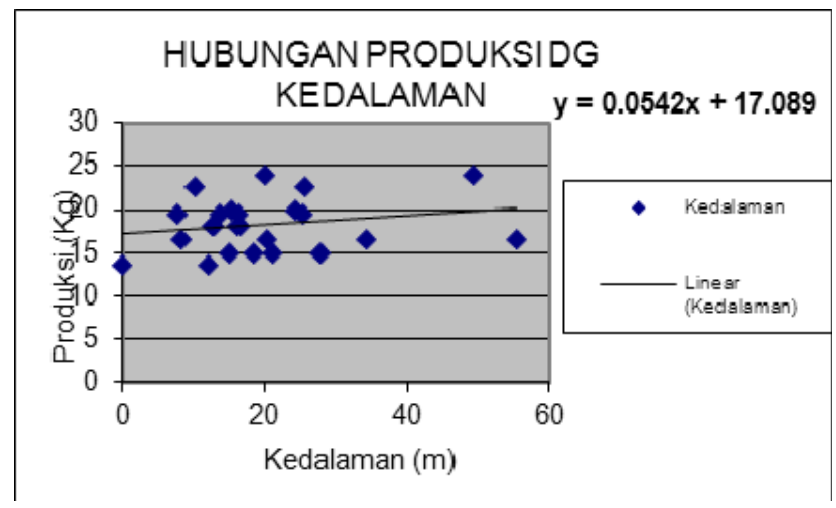

Gambar 2. Grafik hubungan linier produksi dengan kedalaman perairan

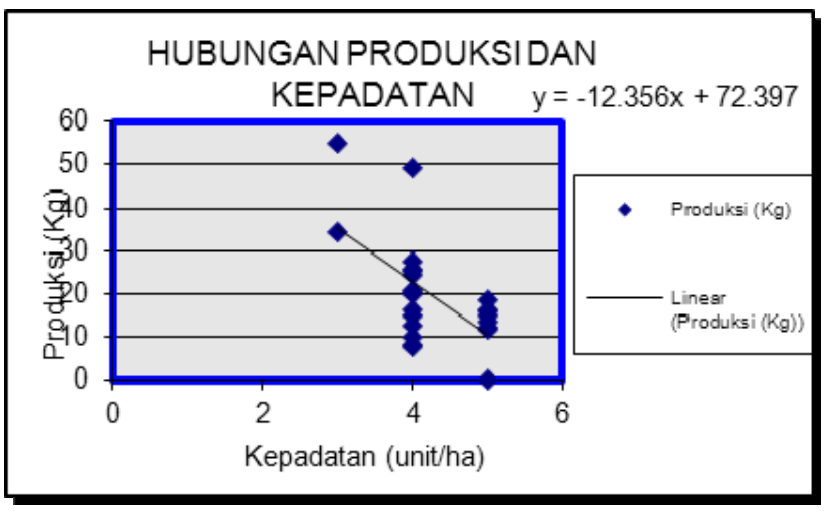

Gambar 3. Grafik hubungan linier produksi dengan kepadatan
Dari persamaan grafik hubungan tunggal antara produksi $(\mathrm{Y})$ dengan kepadatan $\left(\mathrm{X}_{1}\right)$ diatas didapatkan bahwa dalam keadaan konstan $(\mathrm{X}=0)$ produksi hasil tangkap bernilai positif. Dari garis linear terlihat bahwa makin tinggi kepadatannta maka semakin sedikit produksi hasil tangkapnya.

\subsubsection{Analisis Hubungan Input-Output}

a. Produksi dengan kepadatan

- Model lengkap

Dari persamaan model lengkap sebagai berikut :

$\mathrm{Y}=319-8,20 \mathrm{X}_{1}+0,236 \mathrm{X}_{1}^{2}-101 \mathrm{X}_{2}+10,4 \mathrm{X}_{2}^{2}+0,484 \mathrm{X}_{3}-0,12 \mathrm{Z}$

Didapatkan turunan produksi $(\mathrm{Y})$ terhadap kepadatan $\left(\mathrm{X}_{2}\right)$ : $\mathrm{Y}^{\prime}=-101+20,8 \mathrm{X}_{2}$; didapatkan nilai $\mathrm{X}_{2}=4,855$ sehingga kepadatan optimalnya adalah $4,855 \approx 5$ unit/ha

- Model tunggal

Dari hasil analisis data secara kuadratik didapatkan persamaan sebagai berikut :

$\mathrm{Y}=221,141-84,5414 \mathrm{X}+8,58143 \mathrm{X}_{2}$

Dari hasil differensial/turunan persamaan diatas didapatkan nilai $\mathrm{X}$ optimal untuk kepadatan adalah 4,9258 unit/ha $\approx 5$ unit/ha.

b. Produksi dengan kedalaman perairan

- Model lengkap

Dari persamaan model lengkap sebagai berikut :

$\mathrm{Y}=319-8,20 \mathrm{X}_{1}+0,236 \mathrm{X}_{1}^{2}-101 \mathrm{X}_{2}+10,4 \mathrm{X}_{2}{ }^{2}+0,484 \mathrm{X}_{3}-0,12 \mathrm{Z}$

Didapatkan turunan produksi $(\mathrm{Y})$ terhadap kedalaman perairan $(\mathrm{X} 1)$ : $\mathrm{Y}^{\prime}=-8,20+0,472 \mathrm{X}_{2}$; didapatkan nilai $\mathrm{X}_{1}=17,372$ sehingga kedalaman perairan yang optimal adalah $17,372 \approx 17 \mathrm{~m}$. dari perhitungan tersebut disarankan agar untuk mendapatkan hasil tangkap yang optimal, maka kedalaman perairan yang disarankan adalah $\geq 17 \mathrm{~m}$.

- Model tunggal

Dari hasil analisis data secara kuadratik didapatkan persamaan sebagai berikut :

$\mathrm{Y}=25,3738-0,00571 \mathrm{X}-0,000109 \mathrm{X}_{2}$

Dari hasil turunan persamaan diatas didapatkan nilai $\mathrm{X}$ optimal untuk kedalaman perairan adalah 26,192 $\approx$ 26,2 m. Dari perhitungan kedua model tersebut disarankan agar untuk mendapatkan hasil tangkap yang optimal, maka kedalaman perairan yang diperbolehkan bagi bagan tancap adalah $\geq 26,2 \mathrm{~m}$.

Mengingat operasi penangkapan bagan tancap terbatas pada kedalaman sampai $24 \mathrm{~m}$, maka disarankan operasi penangkapan pada kedalaman $\geq 26,2 \mathrm{~m}$ menggunakan bagan apung.

\subsubsection{Koefisien determinasi $\left(\mathrm{R}^{2}\right)$}

Koefisien determinasi yang didapat dari persamaan ini sebesar 0,55 yang berarti bahwa perubahan produksi (hasil tangkap) dapat dijelaskan leh faktor-faktor yang mempengaruhi yang terdapat dalam model sebesar $55 \%$. Sedangkan sisanya $45 \%$ disebabkan oleh faktor-faktor lain yang tidak tercakup dalam penelitian ini, seperti misalnya fishing ground, pengaruh faktor alam seperti musim dan 
arus laut yang sulit dikontrol dan dapat berubah-ubah setiap saat.

\subsubsection{Uji F}

Hasil uji F-Hitung sebesar 3,579 lebih besar dari FTabel sebesar 2,53 pada tingkat kepercayaan 95\%. Hal ini berarti berpengaruh nyata, sehingga model persamaan yang disusun ini layak digunakan untuk menduga adanya hubungan antara peubah bebas (X) dan peubah tak bebas (Y) dan peubah dummy (Z).

\subsubsection{Uji t}

\section{a. Kepadatan}

Kepadatan disini adalah satuan unit alat tangkap per ha $\left(100 \mathrm{~m}^{2}\right)$ dengan asumsi bila terdapat 4 unit/ha adalah padat.

Analisis uji-t menunjukkan bahwa kepadatan memberikan pengaruh yang nyata terhadap hasil tangkap (produksi). Nilai t-hitung 2,268 lebih besar dari t-tabel 2,11 dengan selang kepercayaan $97,5 \%$, nilai probabilitas (sig) 0,037 lebih besar dari 0.05 berarti pengaruh kepadatan signifikan. Diduga kepadatan berpengaruh terhadap hasil tangkap, kepadatan dengan angka lebih tinggi dalam 1 ha akan mengurangi hasil tangkap tiap unit alat tangkapnya, sebaliknya kepadatan dengan angja rendah (lebih sedikit) akan memberikan peluang bagi tiap unit alat tangkapnya untuk mendapatkan hasil tangkap yang lebih banyak, karena saingan juga lebih sedikit dalam operasi penangkapan.

\section{b. Kedalaman perairan}

Analisis uji-t menunjukkan bahwa kedalaman perairan memberikan pengaruh terhadap hasil tangkap, nilai thitung 1,058 lebih besar dari nilai t-tabel 0,863 dengan selang kepercayaan $80 \%$. Hal ini sesuai dengan keadaan di lapang dimana beberapa hal juga mempengaruhi, bila kedalaman makin dalam maka lama menaikkan jaring makin lama karena arus dibawah permukaan makin dalam makin kencang, sehingga dapat memperlambat naiknya jaring yang berarti waktu menaikkan jaring juga makin lama, hal ini berakibat ikan-ikan yang sudah berasa diatas jaring saat jaring masih ada dalam perairan memiliki kesempatan untuk melarikan diri menjauh dari jaring agar tidak tertangkap, akibatnya hasil tangkap juga menurun.

\section{c. Dummy waktu}

Dalam menentukan waktu penangkapan nelayan menentukan waktu penangkapan berdasarkan penanggalan Jawa yang dipengaruhi oleh waktu gelap dan waktu terang bulan. Dummy waktu yang dimaksud disini adalah waktu penangkapan yang digolongkan pada waktu gelap dan terang bulan. Waktu gelap bulan adalah pada tanggal 21-9 sedangkan waktu terang bulan pada tanggal 10-20. Pada waktu penelitian didapatkan masing-masing satu periode waktu gelap dan terang. Hasil tangkap (produksi) dengan satuan $\mathrm{kg} /$ trip dirata-rata berdasarkan waktu gelap dan waktu terang, hasilnya menunjukkan bahwa rata-rata hasil tangkap pada waktu gelap lebih besar daripada pada waktu terang. Sehingga hasil tangkap untuk waktu gelap diberi skor 1 dan untuk waktu terang diberi skor 0 .
Hasil analisis uji-t menunjukkan bahwa dummy waktu tidak begitu memberikan pengaruh terhadap hasil tangkap, dengan nilai t-hitung 0,032 yang kecil sekali sehingga dummy mmang tidak memberi pengaruh yang berarti. Hal ini sesuai dengan keadaan di lapang dimana meskipun waktu blan gelap ataupun terang tidak begitu mempengaruhi waktu operasi penangkapan, meskipun dalam keadaan bulan terang khusus nelayan bagan tancap tetap melaut berbeda dengan nelayan-nelayan besar yang memilih tidak melaut pada saat bulan terang. Nelayan bagan tancap tetap melaut pada waktu bulan terang karena nelayan yang lain tidak melaut dengan motivasi bahwa harga hasil tangkapannya akan lebih mahal karena sepinya ikan hasil tangkap yang didaratkan di PPI.

\section{Simpulan dan Saran}

\subsection{Simpulan}

Berdasarkan hasil penelitian ini, maka didapatkan beberapa kesimpulan :

- Kepadatan alat tangkap bagan tancap sangat mempengaruhi produktifitas alat tangkapnya, bahwa semakin tinggi angka kepadatan maka akan mengakibatkan semakin menurunnya produktifitas alat tangkap.

- Kedalaman perairan juga berpengaruh dimana semakin dalam perairan alat tangkap maka semakin banyak hasil tangkapnya.

- Faktor-faktor lain seperti dummy waktu dan lama hauling kurang berpengaruh terhadap hasil tangkap

- Angka kepadatan yang optimal adalah $<5$ unit/ha

- Kedalaman perairan yang optimal untuk bagan tancap adalah $\geq 26,2 \mathrm{~m}$

\subsection{Simpulan}

- Bagi kalangan akademik perlu adanya penelitian lebih lanjut mengenai faktor-faktor lain yang tidak tercakup dalam penelitian ini

- Sangat dianjurkan untuk operasi bagan pada kedalaman $\geq 26,2 \mathrm{~m}$. Berdasarkan teknologi yang ada saat ini dianjurkan untuk menggunakan bagan apung

\section{Daftar Pustaka}

Anonymous. 1985. Bahan Baku Jaring. Direktorat Penyuluhan Perikanan. Direktur Jendral Perikanan. 24 hal

. 2001. Fishcode Management. Food And Agriculture Organization Of The United Nations. 33 hal

2003. Laporan Statistik Perikanan Jawa Timur Tahun 2002. Dinas Perikanan Propinsi Daerah Tingkat I Jawa Timur. Surabaya.

2004. Monografi Sumberdaya Perikanan dan Kelautan Muncar. Cabang Dinas Perikanan dan Kelautan Muncar. 31 hal

2004. Laporan Tahunan Tahun 2003. Dinas Perikanan dan Kelautan Kabupaten Banyuwangi . 67 hal

Arikunto, S. 1996. Metodologi Penelitian. PT. Rineka Citra. Jakarta. 378 hal 
Birowo, S. 2001.Oseanografi Perikanan (Fishery Oceanography). Dalam: Penuntun Pengkajian Stok Sumberdaya Ikan Perairan Indonesia. Badan Riset kelautan dan Perikanan-DKP dengan Pusat Penelitian OseanografiLIPI. Jakarta.

Darmawan, O.S., D.G.R Wiadnya., Martinus dan D. Setyohadi. 2001. Laporan Akhir Pemetaan Pemanfaatan Sumberdaya Ikan Di Selat Madura, Laut Jawa dan Laut Wilayah Propinsi Bagian Selatan. Fakultas Perikanan Universitas Brawijaya. Malang.

Muhammad, S. 1991. Dasar-Dasar Metodologi Penelitian dan Rancangan Percobaan. Bagian Manajemen Perikanan Program Pemanfaatan Sumberdaya Perikanan. Fakultas Perikanan. UNIBRAW. Malang.

Nazir, M. 1999. Metode Penelitian. PT.Ghalia Indonesia. Jakarta. 622 hal
Subani, W dan H.R. Barus. 1988. Alat Penangkapan Ikan Dan Udang Di Indonesia. Balai Penelitian Perikanan Laut, Departemen Pertanian. Jakarta. 248 hal

Sugiarto. 1992. Tahap Awal + Aplikasi Analisis Regresi. Andi Offset. Yogyakarta. 115 hal

Walpole, Ronald E. 1982. Pengantar Statistika. PT. Gramedia Pustaka Utama. Jakarta. 515 hal

Widianto. 2001. Tipe Perikanan Tangkap Berdasarkan Karakteristik Wilayah Perairan. Dalam: Penuntun Pengkajian Stok Sumberdaya Ikan Perairan Indonesia. Badan Riset kelautan dan Perikanan-DKP dengan Pusat Penelitian Oseanografi-LIPI. Jakarta.

www.pelabuhanperikanan.or.id www.dkp.or.id

(C) 2015 by the authors; licensee Udayana University, Indonesia. This article is an open access article distributed under the terms and conditions of the Creative Commons Attribution license (http://creativecommons.org/licenses/by/3.0/). 